Ensino, Saúde e Ambiente -V10 (3), pp.16-33, Dez. 2017

\title{
BIOLOGIA CELULAR EM REVISTA: ANALISE DE TEXTOS DE DIVULGAÇÃO CIENTÍFICA
}

\section{CELLULAR BIOLOGY IN REVIEW: ANALYSIS OF SCIENTIFIC DISCLOSURE TEXTS}

\author{
Carlos Alberto Andrade Monerat ${ }^{1}$, Marcelo Borges Rocha ${ }^{2}$ \\ ${ }^{1}$ Centro Federal de Educação Tecnológica Celso Suckow da Fonseca (CEFET-RJ) / Laboratório de \\ Divulgação Científica e Ensino de Ciências / carlos.monerat@gmail.com \\ ${ }^{2}$ Centro Federal de Educação Tecnológica Celso Suckow da Fonseca (CEFET-RJ) / Laboratório de \\ Divulgação Científica e Ensino de Ciências / rochamarcelo36@ yahoo.com.br
}

\begin{abstract}
RESUMO
A Divulgação Científica visa aproximar o conhecimento científico das pessoas, permitindo compreender a ciência e os processos pelos quais passam a natureza e os organismos vivos. A Biologia Celular, como uma importante disciplina para as diversas áreas de formação em saúde pode ser apresentada pelos meios de divulgar a ciência, conforme já realizado pelas mídias impressas. Neste caso, os critérios adotados para abordar e divulgar seus conceitos devem contribuir para uma sólida formação, tanto no campo acadêmico, quanto no profissional. Este estudo analisou os textos relacionados à Biologia Celular em quatro revistas científicas de grande circulação no Brasil, seguindo alguns critérios, como o total, o destaque e os erros conceituais decorrentes dos recursos linguísticos relacionados à algumas matérias publicadas. Na pesquisa percebeu-se que a Biologia Celular é amplamente abordada nessas revistas, com 601 textos, em 273 exemplares. Assim, a importância da Biologia Celular é percebida na quantidade considerável de textos publicados nas revistas de Divulgação Científica investigadas na pesquisa, as quais primam por uma linguagem mais simples e que se aproxima mais do público leigo, e por conta disso, despertam mais a atenção do leitor. Porém, em alguns casos, este tipo de escrita pode incidir em inconsistências e erros conceituais no conteúdo das reportagens, contribuindo de forma negativa na construção do conhecimento científico.
\end{abstract}

Palavras-Chave: Biologia Celular; Divulgação Científica; Mídia Impressa; Ensino de Ciências; Educação.

\begin{abstract}
:
The Scientific Disclosure aims to near scientific knowledge to the people, making them understand the science and their processes through which passes the nature and the living organisms. The Cell Biology, as an important course for different graduations areas on health, can be presented by means of disseminating science, as already made by printed media. In this case, the adopted criteria to approach and disseminating must aim contribute to a solid formation, both in academic and professional fields. This study analyzed four scientific mass circulation magazines in Brazil, and their related Cell Biology texts published in contained in them, following specific criteria, such the total, the emphasis and the conceptual errors due to language resources related to some published materials. In the research, was noticed that the Cell Biology is widely addressed in the magazines, with 601 texts, in 273 copies. Thus, the importance of Cell Biology is perceived in the considerable amount of texts published in the journals of


Scientific Divulgation investigated in the research, which emphasize by a simpler language and that is closer to the lay public, and because of this, they attract more attention the reader. However, in some cases, this type of writing can affect more inconsistencies and conceptual errors in the content of the reports, contributing in a negative way in the construction of scientific knowledge.

Key words: Cell Biology; Scientific Disclosure; Printed Media; Science teaching; Education.

\section{INTRODUÇÃO}

$\mathrm{O}$ conhecimento de temas relacionados às Ciências Biológicas tem mostrado grande relevância em diferentes segmentos da sociedade, fornecendo contribuições cada vez maiores à saúde, ao ambiente e ao desenvolvimento tecnológico e industrial. Integram-se também ao desenvolvimento de novas tecnologias e inovações científicas, as quais se relacionam, dentre outras, à técnicas de clonagem, ao estudo do genoma, do potencial das células-tronco nas suas diversas terapias, no desenvolvimento de fármacos, dentre outros (LEGEY; JURBERG e COUTINHO, 2009; LEITE, 2000).

A Biologia Celular é uma área da biologia que perpassa e envolve muitos temas dentro de setores importantes da sociedade, como saúde, tecnologia, indústria, agricultura, pecuária, alimentos, meio ambiente, dentre outros, suscitando discussões de ordem política, ética, econômica e social. Por isso vem se constituindo como importante componente curricular das Ciências Biológicas, pois objetiva proporcionar conhecimentos a respeito dos seres vivos em relação a sua constituição mais básica, que é a célula. Este contexto abrange também os diversificados tipos, componentes, estruturas e funções celulares. A partir daí, a célula passa a ser analisada em seus mais variados aspectos morfológicos e fisiológicos e em suas interações com o ambiente, permitindo perceber que a complexidade resultante de todos estes processos vai contribuir para um adequado funcionamento dos organismos, reforçando a sua condição de representar a unidade fundamental e a peça chave para a formação e constituição da vida (AMABIS e MARTHO, 2012; CAMPBELL et al., 2010; LINHARES e GEWANDSZNAJDER, 2014; SILVA, 2000).

Mediante tais perspectivas, o conhecimento científico e, por conseguinte, a educação científica passam a assumir certo protagonismo (CACHAPUZ et al. 2005), já que este tipo de conhecimento torna-se necessário nos diversos aspectos da vida, principalmente quando incidem em caminhos que levam à escolhas determinantes para a sociedade, adquirindo, assim, uma importância ímpar na tomada de decisões e na 
aplicação dos saberes produzidos, tornando-se uma estratégia para o desenvolvimento coletivo.

Praia, Gil-Pérez e Vilches (2007) acreditam que o conhecimento científico deve tornar possível, não somente a compreensão dos problemas, mas também das opções para solucioná-los, uma vez que muitos dos acontecimentos se baseiam em fatos cotidianos, sobre os quais deve haver o entendimento e a noção sobre como se posicionar a respeito. Mas para isso, tal conhecimento deve chegar às pessoas numa linguagem acessível, para não se ver abdicada sob o argumento de que a sua demonstração se faz dentro de uma complexidade superestimada.

Neste contexto, a Divulgação Científica (DC) pode atuar como uma estratégia de aproximação entre o conhecimento científico e o público em geral, pois, de acordo com Valério e Bazzo (2006) esta deve ser compreendida como um instrumento no campo da comunicação a serviço da educação e das ciências. Portanto, a DC assume o importante papel de informar a uma grande parte da população acerca dos conhecimentos científicos e das tecnologias que, pretensamente, ajudam a melhorar a vida das pessoas e que dão suporte aos desenvolvimentos econômicos e sociais.

Como parte intrínseca da DC, as mídias impressas se tornam uma vertente que oferece possibilidades para o aproveitamento das potencialidades proporcionadas pelo conhecimento científico, que a partir dos seus textos de escopo técnico, se propõem de forma contextualizada e atual, utilizando uma linguagem simples, a aproximar este conteúdo das pessoas, tornando compreensíveis muitos dos seus aspectos para diferentes perfis de público (BERTOLLI FILHO, 2007; MARTINS et al., 2004).

Estudos como os de Legey, Jurberg e Coutinho (2009) já revelaram que a DC na área de Biologia Celular apresenta relevante papel para a informação, com perfil heterogêneo em relação à importância dada pelos veículos de divulgação e enfoque majoritariamente científico das matérias, com diferentes tipos de abordagens e tendo como referências, em casos excepcionais, unicamente periódicos científicos internacionais.

Assim sendo, o objetivo deste trabalho foi analisar textos de DC concernentes à Biologia Celular publicados em revistas de grande circulação nacional, seguindo critérios específicos como, a totalização, o destaque dado às matérias publicadas, além dos possíveis erros conceituais decorrentes dos recursos linguísticos contidos nestes textos, confirmando a sua excepcionalidade, pois, na literatura, as pesquisas que 
Ensino, Saúde e Ambiente-V10 (3), pp.16-33, Dez. 2017

envolvem a abordagem de textos voltados à Biologia Celular pela Divulgação Científica, dentro deste recorte temporal, faz com que os estudos direcionados para este estado da arte apresentem lacunas.

\section{METODOLOGIA}

O presente trabalho se baseia em uma pesquisa descritiva, que segundo Gil (2008) é aquela que apresenta a utilização de técnicas padronizadas de coleta de dados, além da observação sistemática do objeto de pesquisa como uma de suas peculiaridades.

A principal forma de interpretação dos dados foi através da análise de conteúdo, que segundo Bardin (2009), se traduz em um conjunto de técnicas de análise das comunicações que utiliza procedimentos sistemáticos e objetivos para a descrição do conteúdo das mensagens. Nesta pesquisa, especificamente, alguns dados quantitativos foram analisados em conjunto com os dados qualitativos, os quais possuíram caráter contundente na discussão dos resultados.

A presente investigação foi dividida em etapas: em um primeiro momento foi realizado um levantamento das revistas de DC de maior circulação no Brasil e, consequentemente, mais conhecidas, que apresentavam regularidade nas suas publicações e que poderiam abordar temas relacionados à Biologia Celular em suas matérias. Assim sendo, por atender a todos os critérios estabelecidos e oferecer mais fácil acesso aos exemplares publicados, foram escolhidas as revistas Ciência Hoje, Galileu, Scientific American Brasil e Superinteressante, todas com publicações regulares, de periodicidade mensal, e que ainda contam com edições extras, sobre determinados temas específicos.

A escolha desses periódicos também se deveu ao fato de serem materiais impressos de DC que já receberam certificações e premiações, com grande tiragem e circulação por todo o país. Portanto, possuem representatividade dentre os veículos que se propõe a divulgar a ciência para o público brasileiro (GOMES, DA POIAN e GOLDBACH, 2012).

Foram analisados exemplares publicados nos últimos cinco anos, compreendendo o período entre janeiro de 2011 a dezembro de 2015. Este intervalo foi definido levando-se em consideração que cada revista escolhida conta com edições mensais, além de edições extras, perfazendo uma quantidade total de 273 exemplares.

A busca foi realizada através dos acervos digitais e das edições impressas das revistas escolhidas para o desenvolvimento do trabalho, durante o período mencionado. 
$\mathrm{Na}$ verificação para a seleção dos textos foi constituído um processo de busca e organização sistemática das edições coletadas, através da leitura minuciosa dos seus conteúdos. Após esta etapa, uma catalogação com o objetivo de se constituir um banco de dados foi realizada, e desse modo, possibilitou-se estabelecer, de imediato, a relação da quantidade de textos, reportagens, matérias e artigos publicados em cada edição, a fim de compreendê-las e proceder com a sua organização, para critérios estatísticos.

A análise e discussão do perfil de cada revista seguiram determinados parâmetros, tais quais o total de matérias relacionadas à Biologia Celular; os temas relacionados à Biologia Celular que foram contemplados, o destaque dado às matérias, de acordo com a maneira como estas foram publicadas (se ocupa a página inteira; se ocupa meia página, se está inserida em apenas uma pequena parte da página, ou até mesmo se a publicação se resume a uma observação ou nota de rodapé) e os recursos linguísticos aplicados nos textos.

\section{RESULTADOS E DISCUSSÃO}

Na investigação foi primeiramente constatado um total de 25 matérias, em média, para cada uma das quatro revistas investigadas, dentro do recorte temporal estabelecido, chegando-se a um número total de 7.030 textos pesquisados, conforme mostra a Tabela 1 .

Tabela 1: Total de textos referentes à Biologia Celular encontrados em comparação com o total de matérias publicadas em cada revista pesquisada.

\begin{tabular}{lccc}
\hline \multicolumn{1}{c}{ Revistas } & $\begin{array}{c}\text { Total de matérias } \\
\text { por edição (média) }\end{array}$ & $\begin{array}{c}\text { Total de matérias no } \\
\text { período pesquisado }\end{array}$ & $\begin{array}{c}\text { Matérias sobre } \\
\text { Biologia Celular }\end{array}$ \\
\hline \hline Superinteressante & 30 & 2940 & 143 \\
Galileu & 26 & 1560 & 119 \\
Scientific American Brasil & 22 & 1320 & 172 \\
Ciência Hoje & 22 & 1210 & 167 \\
\hline \multicolumn{1}{c}{ Totais } & $\mathbf{1 0 0}$ & $\mathbf{7 0 3 0}$ & $\mathbf{6 0 1}$ \\
\hline
\end{tabular}

Fonte: os autores.

Em termos percentuais, a figura 1 ilustra a contribuição de cada revista em relação ao total de matérias/artigos/textos produzidos durante o período da pesquisa, revelando que a Biologia Celular ocupa percentuais representativos de seus temas publicados, se considerarmos que ela deve dividir espaço com os demais temas científicos e tecnológicos, em revistas de grande abrangência, as quais além do perfil 
científico, devem também primar para os propósitos comerciais.

Figura 1: Percentual das matérias sobre Biologia Celular em relação ao total publicado.

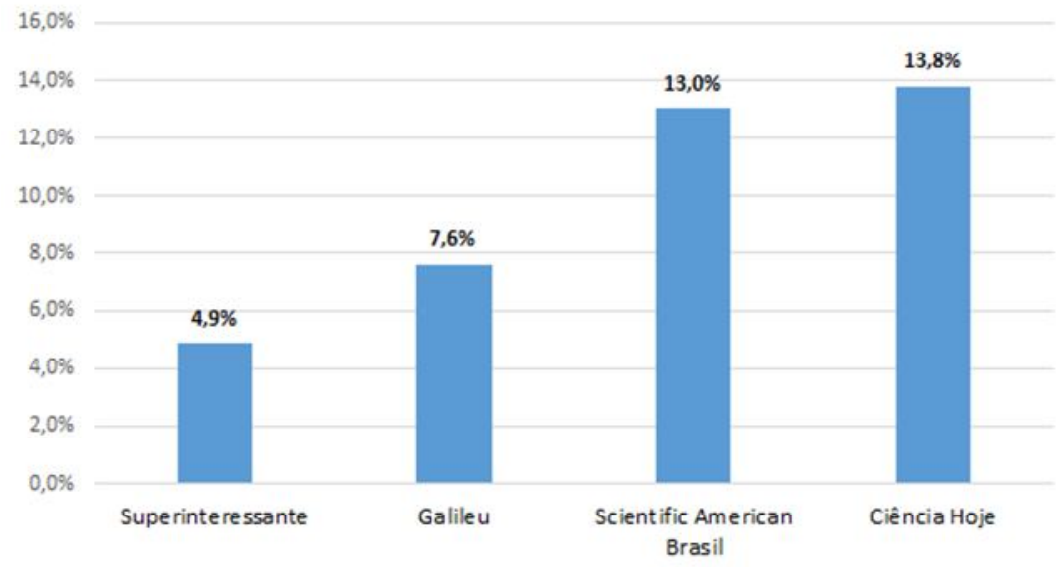

Fonte: os autores.

Desse modo, uma relevante quantidade de publicações sobre Biologia Celular está representada por 601 textos/matérias/artigos publicados, em um total de 273 exemplares analisados. Ao se levar em consideração o período pesquisado (cinco anos), há uma média geral de 2,2 artigos de Biologia Celular por revista, conforme mostrado na Tabela 2. Este dado revela que, dentre todas as reportagens apresentadas, voltadas genericamente para ciência e tecnologia, pouco mais de duas matérias são relacionadas à Biologia Celular para cada revista publicada.

Tabela 2: Quantidade e média de textos encontrados nas revistas pesquisadas.

\begin{tabular}{|c|c|c|}
\hline Revistas & matérias & exemplares \\
\hline Superinteressante & 143 & 98 \\
\hline Galileu & 119 & 60 \\
\hline Scientific American Brasil & 172 & 60 \\
\hline Ciência Hoje & 167 & 55 \\
\hline Totais & 601 & 273 \\
\hline Matérias por exemplar (média) & & 2 \\
\hline
\end{tabular}

Fonte: os autores.

Tal fato deve-se a importância do conhecimento sobre a Biologia Celular para compreensão de conceitos, como células-tronco, terapia gênica, sequenciamento do genoma de organismos diversos, transgênicos, clonagem, dentre outros, e as suas possibilidades de aplicações práticas, conforme demonstrado em Legey, Jurberg e Coutinho (2009).

A revista que mais apresentou matérias relacionadas à Biologia Celular no período pesquisado foi a Scientific American Brasil e a com o menor número foi a 
Revista Galileu, conforme mostra a figura 2.

Figura 2: Quantidade de matérias encontradas por revista pesquisada

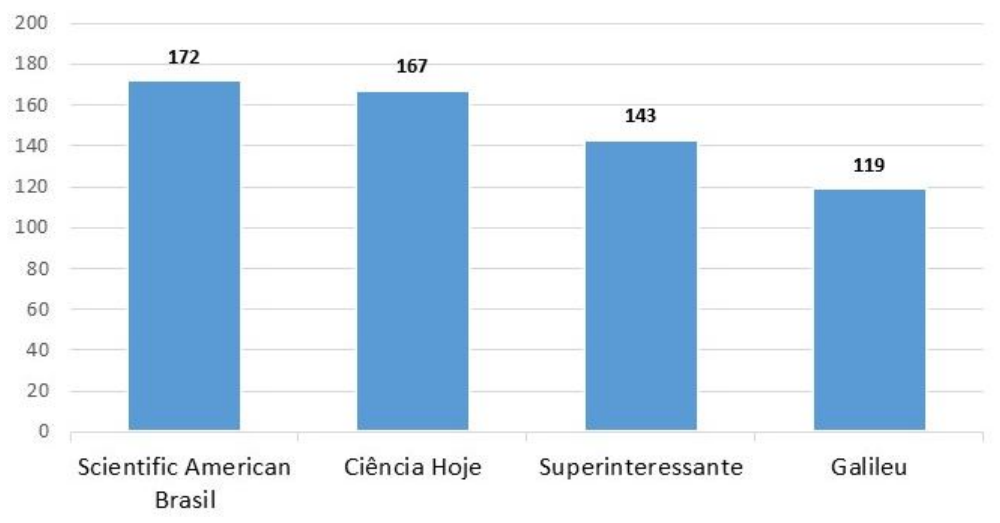

Fonte: os autores.

Torres (2001) analisa que a biologia da célula ocupa um grande espaço na mídia. Para o autor, alguns dados mostram os vários motivos desta popularidade, dentre eles a preocupação com a saúde e o bem-estar dos indivíduos, a interferência no código genético e, consequentemente os seus desdobramentos, além das doenças sexualmente transmissíveis e até mesmo os cuidados com o meio ambiente. A massiva divulgação e popularização da Biologia Celular trazem novas incumbências, especialmente para os professores da educação básica e do ensino superior, os quais são, muitas vezes, as fontes mais confiáveis de esclarecimento dos estudantes.

Nota-se que as revistas Ciência Hoje e Scientific American Brasil são as que apresentam os maiores percentuais de publicações sobre Biologia Celular em relação ao número total de exemplares publicados no período pesquisado, com valores em torno de $13,8 \%$ e $13 \%$ das matérias, respectivamente. É possível que esta tendência se deva ao perfil mais específico em relação a temas estritamente científicos dos referidos periódicos em relação aos outros com os menores percentuais (Galileu e Superinteressante), já que os últimos mencionados apresentam um perfil mais generalista e comercial, abrangendo um conteúdo mais universalizado, tentando atender a um escopo mais diversificado de público, com temas igualmente variados.

Temas como a Biotecnologia, Microbiologia e Imunologia, que apresentaram maior incidência de matérias, conforme mostrado na figura 3, têm a sua importância atrelada ao um perfil interdisciplinar, onde as suas aplicações encontram lugar em vários segmentos da sociedade, como na indústria farmacêutica, através do desenvolvimento e na produção e melhoramento de remédios, na produção de vacinas 
com a utilização de proteínas recombinantes, no estabelecimento de terapias gênicas e demais estratégias para o tratamento de doenças em animais e vegetais.

Figura 3: Totalização dos temas trazidos pelas revistas.

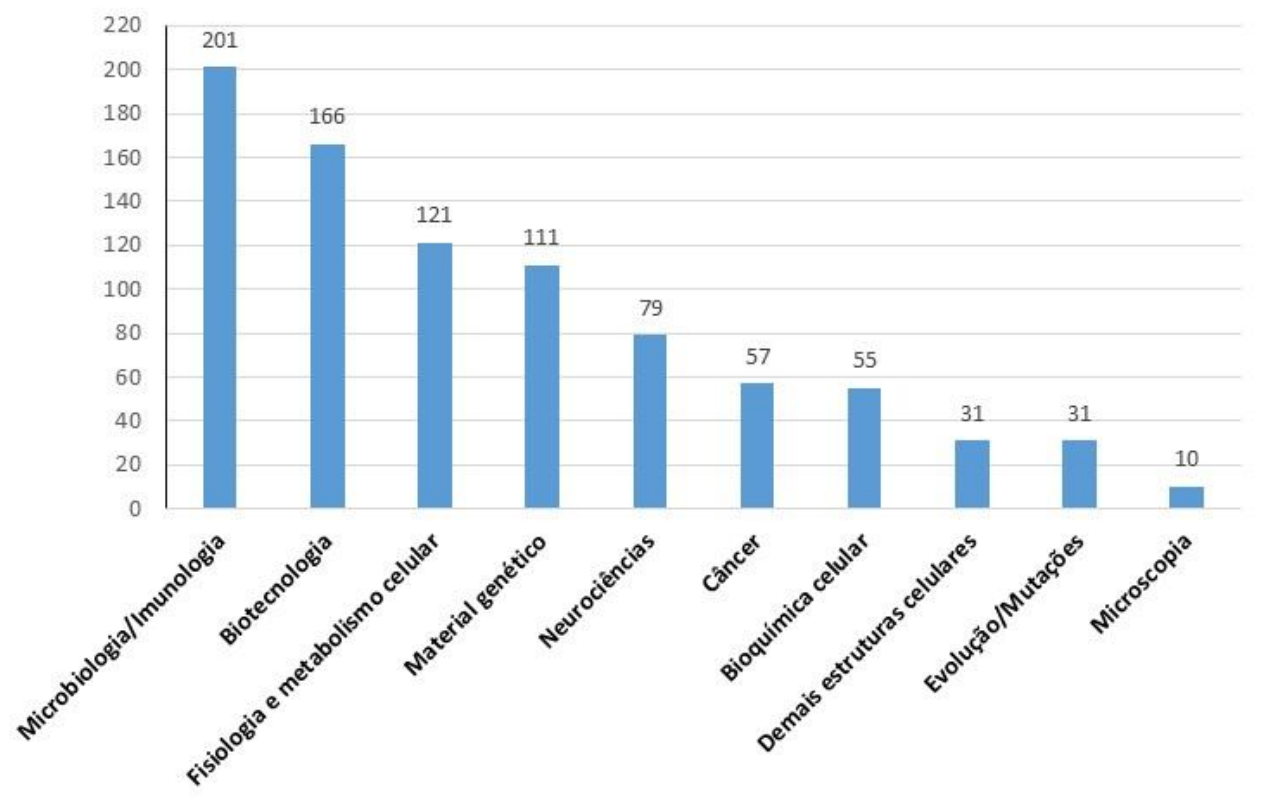

Fonte: os autores.

A partir dessas evidências, surge o conceito das doenças emergentes e reemergentes, que seriam aquelas cuja incidência em humanos vem aumentando nas últimas décadas ou ameaça aumentar num futuro próximo, e onde Luna e Silva Jr. (2013), no caso específico das doenças infecciosas inferem que:

O conceito [...] incorpora claramente dois focos principais: o surgimento de novos problemas de saúde relacionados a novos agentes infecciosos; e a mudança de comportamento epidemiológico de velhas doenças infecciosas, incluindo a introdução de agentes já conhecidos em novas populações de hospedeiros suscetíveis e outras alterações importantes no seu padrão de ocorrência. Esses fenômenos da emergência e reemergência de doenças infecciosas estão relacionados a diversos fatores, desde as profundas e rápidas mudanças que têm ocorrido em aspectos demográficos, socioeconômicos e ambientais, além daqueles relacionados ao desempenho do setor saúde, das mudanças e mutações nos microrganismos, até a possibilidade de manipulação de agentes infecciosos com vistas ao desenvolvimento de armas biológicas (LUNA, SILVA JR., 2013. pp. 123).

Este processo, segundo os autores (op cit), mostra a constatação de que a convivência da espécie humana com os agentes infecciosos, em um ambiente continuamente modificado pela ação humana sempre existiram, e que as doenças infecciosas e seus agentes continuarão em seu movimento, em direção ao controle, eliminação e eventualmente, erradicação, mas também com a possibilidade de 
percorrerem a direção oposta, emergindo ou reaparecendo, em determinadas situações.

Em relação às doenças não infecciosas, Batistella (2013) aponta que estas também se mostram como um problema de preocupação central, já que a depressão, a hipertensão, o colesterol alto, o excesso de peso, o tabagismo, o alcoolismo e outras dependências químicas estão entre os principais fatores de risco para a maior parte destas doenças. O ritmo acelerado e o estresse causado pela vida nos grandes centros urbanos, a competitividade alta, os subempregos e o desemprego, além das barreiras econômicas e culturais têm tornado inquestionável a tendência de crescimento das doenças não infecciosas no mundo, sinalizando um quadro de difícil enfrentamento e por isso, de interesse da população.

A Biotecnologia, devido à sua importância social, política e econômica para a população apresenta também grande destaque em relação ao número de matérias apresentadas nas revistas pesquisadas.

Esta constatação, pelo menos em parte, se deve ao fato de que o avanço observado nas últimas décadas na Biologia Celular, através da instituição de técnicas para o desenvolvimento de equipamentos especializados e a produção industrial de insumos e reagentes, possibilitaram descortinar a universalidade dos seus princípios básicos, trazendo à tona melhores e mais precisos conhecimentos sobre a estrutura e o funcionamento dos organismos vivos, promoveu um avanço vertiginoso de conhecimentos e uma convergência das demais disciplinas biológicas que, segundo Silva (2000), durante o século XIX e início do século XX, tinham conhecido tão somente um lento acúmulo de informações, sendo que essas conquistas e descobertas tiveram repercussão imediata na esfera biotecnológica.

\footnotetext{
A Biologia Celular e molecular teve grande desenvolvimento e, nos últimos anos, vem atravessando a fase denominada genômica, em que os pesquisadores se concentram na descrição do sequenciamento do repertório de genes de seres vivos (genomas), desde vírus e bactérias até o homem, e na identificação de genes responsáveis por características fenotípicas normais ou patológicas, com a perspectiva de decifrar e definir, nos próximos anos, as informações completas dos repertórios de genes típicos de cada espécie. Ao mesmo tempo, desenvolveu-se um capítulo próprio da informática, a bioinformática, que introduziu metodologias de análise das macromoléculas biológicas e de suas interações, permitindo a experimentação nas telas de computadores, com enorme economia de tempo e de complexas operações de bancada (SILVA, 2000. pp. 60-61).
}

O trecho acima corrobora o destaque dado à Fisiologia, ao metabolismo celular e também ao material genético, através da considerável quantidade de artigos e matérias nessas publicações, que falam da importância do desenvolvimento desses estudos 
também para o tratamento de doenças ligadas aos genes e à hereditariedade.

Outra característica observada é a de que a maioria dos artigos apresenta um perfil multidisciplinar, já que os textos em si abordam várias das temáticas categorizadas. Por isso, cabe ressaltar também essa característica de quase todas as matérias apresentarem enfoques variados, sendo abordados vários temas dentro da Biologia Celular em uma única reportagem. Por isso, ao se analisar as matérias, optouse por classificá-las em quantos temas a mesma estivessem abordando e dando ênfase, caso a matéria apresentasse esta característica. Por isso os totais desta catalogação superaram o número total de matérias encontradas.

Diante da considerável quantidade de reportagens sobre Biologia Celular encontrada, foi realizada uma categorização sobre a importância dada a cada uma delas dentro das revistas, conforme visto na Tabela 3.

Tabela 3: Categorização do destaque dado à Biologia Celular nas revistas publicadas.

\begin{tabular}{cl}
\hline Destaque dado às matérias & \multicolumn{1}{c}{ Categorização } \\
\hline Principal (capa) & $\begin{array}{l}\text { Quando a matéria fazia parte do conteúdo principal/central da revista, integrando a } \\
\text { capa da edição. }\end{array}$ \\
Página(s) inteira(s) & $\begin{array}{l}\text { Quando a matéria apres entou um conteúdo de abordagem, o qual integrou uma ou } \\
\text { mais de uma página inteira da revis ta. }\end{array}$ \\
Meia página & Quando a matéria ocupou, independentemente da sua importância, umespaço em \\
& torno da metade de uma página da revista. \\
Seções curtas & Quando a revista dedicou menos da metade da página ao artigo, por vezes em \\
Notas & seções específicas. \\
& Quando as matérias ocupam menos de um quarto da página.
\end{tabular}

Fonte: os autores.

Estas características obedecem ao perfil de cada revista, tanto em termos de diagramação e layout, bem como o quanto este periódico aproveita os espaços das suas páginas, com finalidades específicas, o que certamente acompanha também um teor comercial e, portanto, que vão além do que as informações puramente científicas possuem de importância. Porém, independentemente de como cada periódico exibe suas reportagens, o objetivo é sempre, segundo Scorsolini-Comin (2012), o de trazer uma linguagem mais atual para a revista, em consonância com os parâmetros da editoração científica adotada por periódicos de expressão nacional e internacional.

Um interessante ponto de observação é que do total de matérias dedicadas à Biologia Celular (601), 277 delas, ou seja, 46,1\% tiveram considerável destaque, seja fazendo parte das capas das edições ou apresentando volumes superiores a mais de uma página inteira. A figura 4 exibe a quantidade total de matérias sobre Biologia Celular e os seus respectivos espaços ocupados nas revistas. 
Figura 4: Destaque dado à Biologia Celular nas revistas.

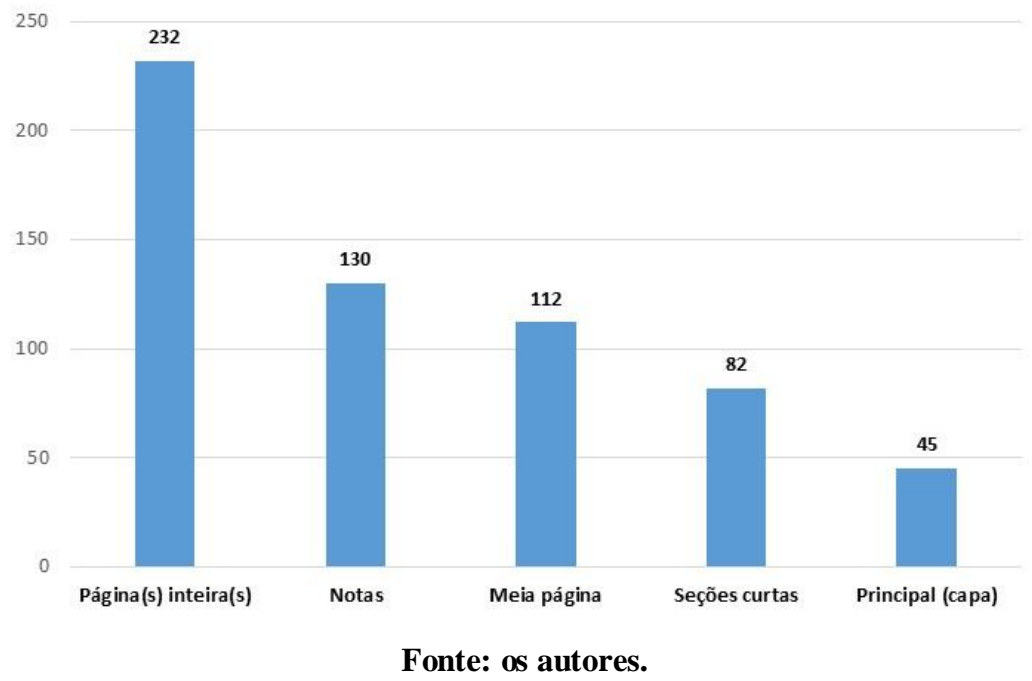

Em relação à análise do destaque dado à Biologia Celular por revista, mostrado na figura 5, foi percebido que a revista Scientific American Brasil é a que apresenta o maior número de matérias com artigos de cunho central, os quais compuseram as capas, além das matérias de destaque, as quais ocupam uma página ou páginas inteiras, se comparadas aos outros periódicos, totalizando 123 matérias de destaque, sendo que dentre essas, 15 eram capa das edições.

Figura 5: Comparativo entre as revistas em relação ao destaque dado às matérias sobre Biologia Celular e sua totalização.

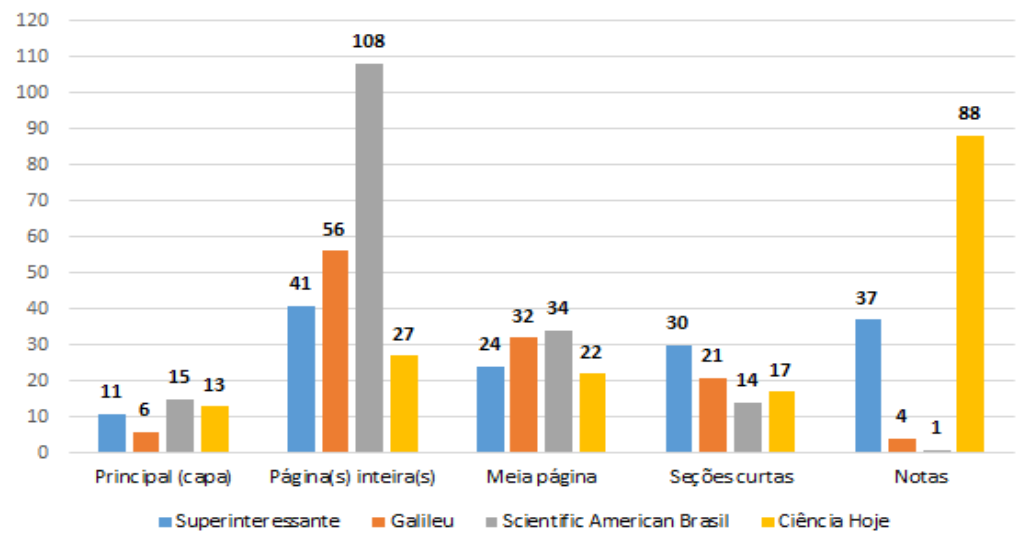

Fonte: os autores.

A revista que apresentou menos matérias de destaque em relação ao todo pesquisado foi a Ciência Hoje, com o total de 40 reportagens de proeminência, embora esta contasse com o maior percentual de matérias sobre o tema. Conclui-se daí, que a revista Ciência Hoje, apesar das muitas publicações sobre Biologia Celular, não procura dar ênfase nessas matérias, sendo que tal fato pode acontecer por motivos variados, que 
vão desde a diluição dos textos em diversas seções menores da revista, ou até mesmo em detrimento a algum outro tema que mereça maior atenção, dada à sua importância ou contexto.

Neste ponto, segundo Gonçalves (2008), a capa da revista funciona como uma propaganda do seu conteúdo, como um recurso para se captar a atenção do leitor. Normalmente as mídias impressas confeccionam as suas respectivas capas com uma reportagem especial, com chamada em letras maiores e que ocupam um considerável espaço dentro do todo disponível no processo de diagramação. As demais reportagens, consideradas menores, ocupam os demais espaços ao redor. Portanto, as matérias mais valorizadas é que terão o devido destaque, com a concernente chamada na capa.

O que deve ficar claro é que a revista Scientific American Brasil foi também a que mais publicou sobre o tema pesquisado, o que pode pesar para que, inevitavelmente a mesma tenha dedicado a este tema várias matérias de destaque. A propósito, embora a revista Galileu tenha tido o menor número de reportagens sobre o tema, é notório o destaque que este recebeu em termos proporcionais.

Se forem somados todos os artigos de Biologia Celular que obtiveram destaques de capa ou em página(s) inteira(s) nas revistas pesquisadas, teremos um total de 277 reportagens, ou seja, 46,1\% de todas as matérias publicadas. Este dado reforça a importância da Biologia Celular na DC, que além do grande número de textos apresentados, quase a metade deles ganharam destaque nessas mídias.

Apesar do destaque dado à Biologia Celular nas revistas de DC, esse número ainda é menor, proporcionalmente, em termos quantitativos, se considerado o período pesquisado, a quantidade de revistas e de exemplares, em relação à outra mídia impressa: o jornal. De acordo com as pesquisas Legey, Jurberg e Coutinho (2009), foram encontradas 231 reportagens envolvendo temas de Biologia Celular veiculadas por um período de dez meses (setembro de 2004 a julho de 2005), em dois jornais de circulação diária e três revistas de circulação semanal no país.

As análises das revistas também mostraram que na maioria das matérias de menor destaque, ou seja, as que ocupam apenas notas ou seções curtas, o conteúdo do texto não apresenta a preocupação com a parte técnica, tampouco esse conteúdo traz referências sobre as pesquisas e/ou se houve conclusão de tais estudos. Aparentemente, o que se está priorizando com tais publicações é somente despertar a atenção do leitor.

Em relação às figuras de linguagem empregadas, os textos dos artigos 
publicados nas revistas, de um modo geral, apresentam uma linguagem bastante clara e objetiva, obviamente, de acordo com a temática escolhida por cada editorial, por isso adotou-se o vocabulário como parâmetro para determinar o quanto a linguagem dos artigos é elaborada. Neste caso, novamente dois grupos são formados, de acordo com a complexidade adotada em cada perfil de periódico.

As revistas Superinteressante e Galileu, com poucas variações entre ambas denotam-se por possuir uma linguagem bastante acessível à maioria das pessoas, mesmo para aquelas que não têm contato com os pressupostos científicos, seja por formação ou interesse. Os termos utilizados não possuem complexidade para o seu adequado entendimento.

Zamboni (2001) alega que o discurso da DC é distinto dos discursos científico, jornalístico e cotidiano, uma vez que é elaborado tendo em vista a acessibilidade de um tipo de receptor que não pertence nem ao âmbito dos cientistas e nem dos repórteres, por isso, com muita frequência, estes periódicos fazem uso de termos com distintas conotações para tornar os assuntos tratados mais claros e até mais atraentes para os leitores, o que incide em erros ou incoerências nos conceitos científicos abordados.

Das revistas analisadas, a Superinteressante foi a que mais incorreu nestas situações. Em sua edição 288, de fevereiro de 2011, ao divulgar um texto sobre as modificações ocorridas no corpo em situações de risco, poderia ser utilizada, pelos autores da matéria, a nomenclatura apropriada ao citar os nomes das estruturas celulares, como por exemplo, no caso das "miofibras", que poderiam dar lugar ao termo miofibrilas ou miócitos, os quais são mais adequados. Ainda, em relação as "miofibras" citadas na reportagem, uma vez representando as células musculares, as mesmas não são apenas “compostas de proteínas" como leva a entender a ambígua redação do texto.

Quanto ao acima exposto, as informações também poderiam estar mais completas quanto ao relato do processo de contração muscular, sem, no entanto, confundir o leitor com termos complexos, conforme relatado em Guyton e Hall (2006), os músculos são compostos por numerosas fibras. Cada uma dessas fibras é formada por centenas a milhares de miofibrilas. Cada miofibrila é também composta por filamentos de miosina e de actina, que são longas moléculas de proteínas, além uma membrana e um revestimento de uma fina camada de material polissacarídeo.

Tais informações, como colocadas no texto da matéria, só não causariam muita confusão ao leitor se este já possuísse um grau de compreensão em Biologia, pelo 
menos, ao nível do ensino médio, uma vez que o conteúdo deixou de fornecer a denominação correta dos componentes celulares em questão, aglutinando por demais o tema proposto.

Mais um exemplo de erro conceitual na revista Superinteressante acontece na edição 297, de nov/2011, quando uma matéria se propõe a relatar uma série de sintomas do organismo quando se leva um susto: "O quê? Aumento de pressão do sangue. Por quê? Junto com constrição de vasos e coração acelerado, transporta rapidamente energia, aumenta a circulação e evita hemorragias." (SUPERINTERESSANTE, edição 297, nov/2011).

O transporte de energia acontece ao nível celular, não sendo a corrente sanguínea determinante para esse transporte. Quando a circulação é aumentada, o risco de hemorragia não é evitado. Pelo contrário, esta tem mais chances de acontecer, já que o sangue está mais intensamente atuando em diferentes pontos do organismo.

Na edição 298, de dez/2011, na matéria “Tratamento pode reverter a síndrome de Down”, o título do texto não levou em consideração o teor da reportagem, em que é tratado o processo de reversão, baseado apenas nos aspectos cognitivos da síndrome, sendo que o fenótipo do indivíduo permaneceria o mesmo, contrariando, assim, o título do artigo, já que a síndrome de Down não seria revertida inteiramente, levando em consideração, tanto nos seus aspectos genotípicos, quanto em termos fenotípicos.

A Superinteressante, dessa vez na edição especial 305 a, em junho de 2012, na matéria intitulada "Somos todos mutantes", é percebido um erro conceitual no trecho: "Lembra dos nucleotídeos, as letras A, T, C e G que formam o gene? São 6 bilhões delas em cada célula do corpo, metade herdada do pai, e outra, da mãe". Neste caso há uma confusão na utilização do termo nucleotídeo, que segundo De Robertis; Hib; Ponzio, (2008); Campbell, (2010); Amabis e Martho, (2012); Junqueira e Carneiro, (2012) e Linhares e Gewandsznajder, (2014) se refere a polímeros constituídos por um fosfato (mais especificamente, ácido fosfórico), uma molécula de açúcar com cinco carbonos (pentose) e uma base nitrogenada. No caso do DNA, o açúcar referido se trata da desoxirribose. No caso das "letras A, T, C e G", estas são as bases nitrogenadas (compostos cíclicos que contêm nitrogênio), que podem ser púricas, representadas pela adenina (A) e guanina $(\mathrm{G})$, ou pirimídicas, representadas pela timina $(\mathrm{T})$ e citosina $(\mathrm{C})$.

Outro erro conceitual encontrado na Superinteressante diz respeito à matéria publicada na edição 306, de julho de 2012, com o título: "Pegar friagem provoca 
resfriado?", onde o artigo tenta esclarecer um tema controverso, já que muitas pessoas costumam associar um fato ao outro. Porém, uma série de incoerências pode provocar uma confusão ao leitor, a começar pelo trecho complementar ao título, em que diz: "Quem causa a doença são vírus, e não o termômetro. O que acontece é que esses microorganismos (sic) estão mais ativos no inverno". No decorrer do texto as incorreções também continuam, como no trecho: "Mas é porque os vírus que causam problemas respiratórios estão mais ativos nessa época do ano. É a mesma coisa que o vírus da dengue. Ele está à toda no verão, porém ninguém fala que é o calor que provoca a doença".

É importante esclarecer que os vírus da gripe não têm maior atividade no inverno, tampouco o da dengue no verão. Os vírus não têm atividade metabólica própria, ao contrário das células vivas, conforme as bactérias, os protozoários, os fungos e etc. Portanto, não se trata de variações sazonais. O vírus da dengue não fica mais ativo no verão, porém, os mosquitos, que são os vetores do vírus, encontram melhores condições de vida e consequentemente, de reprodução nesta estação, e não que o vírus tenha maior atividade neste período. Da mesma forma, o vírus da influenza se acredita que seja mais prevalente no inverno porque as pessoas tendem a ficar mais próximas e em ambientes mais fechados, e não devido a uma atividade (metabolismo) que os vírus não apresentam fora das células.

Ainda na edição 306, de julho de 2012, com o título "Felicidade é definida pelos genes de cada um", um estudo se propôs a identificar o que mais influenciaria na felicidade de uma pessoa, se as experiências que ela tem durante a vida, ou as características previamente escritas em seu código genético. Neste texto, as informações não aparecem de forma completa, faltando descrever de uma forma mais abrangente as análises comparativas dos resultados, pois, para se dizer, em termos genéticos, que um aspecto se sobrepõe a outro, ele precisaria ter colhido outros dados e amostras, como por exemplo, de irmãos gêmeos que viveram em ambientes distintos. Daí, como se pode inferir que o aspecto ambiental é menos importante que o aspecto genético, se ele a pesquisa só colheu dados de pessoas num mesmo ambiente? Na matéria também não é mencionado onde foi publicado tal estudo.

Diante do mencionado, percebe-se que os títulos das matérias possuem objetivo de divertimento e atração, mantendo a tendência das revistas de tentar passar ao leitor a ideia de que o conhecimento pode estar associado ao entretenimento. 
Ensino, Saúde e Ambiente -V10 (3), pp.16-33, Dez. 2017

\section{CONSIDERAÇÕES FINAIS}

As quatro revistas analisadas nesse trabalho apresentam uma quantidade considerável de textos relacionados à Biologia Celular, com 601 textos em um total de 273 exemplares, cujas reportagens podem representar um vasto material que possibilita inúmeras formas de utilização, objetivando valorizar o conhecimento científico atual e, mais ainda, auxiliando o desenvolvimento de uma cultura científica.

Quase metade dos textos, ou seja, 277 matérias, apresentam destaque, sendo 45 mostrados em reportagens de capa, e 232 ocupando mais de uma página. Este resultado representa $46,1 \%$ de todas as matérias sobre Biologia Celular publicadas. As doenças infecciosas e os aspectos relacionados à Biotecnologia foram os temas que mais ocuparam espaço nessas revistas, com $61 \%$ dos textos publicados. Esses resultados refletem a importância dada, pelos periódicos, à relação saúde/doença, que por sua vez, tem sido objeto de interesse das pessoas no mundo inteiro, já que as pesquisas para a descoberta dos sintomas, terapias e a profilaxia de enfermidades são contínuas e os microrganismos, com seus aspectos morfológicos e fisiológicos denotam um papel essencial neste processo.

Outro importante aspecto relaciona-se com o período que a pesquisa avançou, ou seja, nos últimos cinco anos houve grandes ocorrências de doenças, as quais tornaram-se motivo de preocupação por conta de endemias, epidemias e pandemias, em que bactérias, vírus e outros microrganismos, com a sua grande capacidade de adaptação e modificação de suas características, configuram um novo padrão na disseminação de novas e velhas doenças, infecciosas ou não, delineando um perfil epidemiológico complexo e, consequentemente, causando grandes estragos à humanidade.

A biotecnologia, que através do desenvolvimento de equipamentos especializados e a produção industrial de insumos e reagentes, os quais possibilitaram descortinar a universalidade dos seus princípios básicos, revelando conhecimentos inéditos sobre a estrutura e o funcionamento dos organismos vivos mereceu também um grande destaque nas publicações.

Desse modo, a compreensão destas questões ampliará a discussão no campo do ensino científico, no sentido de contribuir como referencial teórico posto à disposição de educadores e pesquisadores. Contudo, todo o contexto trazido pela DC poderá contribuir diretamente para que a assimilação dos conteúdos de Biologia Celular possa 
ocorrer de forma satisfatória, pois em relação ao seu aprendizado, este não se dá de forma diferente dos demais processos de aprendizagem em comparação a quaisquer outros conteúdos da área científica.

Os temas e questões relacionadas à Biologia Celular, que a mídia impressa, por intermédio das revistas de DC, aborda através das suas publicações, além das suas potenciais contribuições na apropriação de saberes e conceitos científicos relativos a este campo da ciência se faz um interessante objeto de estudo, que naturalmente pode se desdobrar em questionamentos no sentido de analisar o que vem sendo divulgado na mídia impressa sobre Biologia Celular e as suas possíveis utilizações junto a futuros professores de ciências e biologia. Sendo assim, o uso de materiais, como os de DC, podem ser alternativas úteis dentro de sala de aula.

\section{REFERÊNCIAS}

AMABIS, J. M.; MARTHO G.R.; Biologia: Biologia das células. v. 1, 3 ed. Moderna. São Paulo, 2012.

BARDIN, L. Análise de Conteúdo. 1 ed. Edições 70, LDA. Lisboa, Portugal, 2009.

BATISTELLA, C.; Saúde, Doença e Cuidado: complexidade teórica e necessidade

histórica. In: Educação Profissional e Docência na Saúde: a formação e o trabalho do Agente Comunitário de Saúde. 2013. Disponível em: <

http://www.epsjv.fiocruz.br/pdtsp/index.php?verifica=1\&area_id=2\&livro_id=6\&arqui vo=ver_conteudo_2> Acessado em: 28 de abril de 2016.

BERTOLLI FILHO, C.; A divulgação científica na mídia impressa: as ciências biológicas em foco. Ciênc. Educ., Bauru, v. 13, n. 3, p. 351-368, Dec. 2007.

CACHAPUZ, A. et al.; (orgs.). A necessária renovação do ensino das ciências. 3 ed. Cortez. São Paulo, 2005.

CAMPBELL, N. A. et al.; Biologia. 8 ed. Artmed. Porto Alegre, 2010.

GIL, A. C.; Como elaborar projetos de pesquisa. 4 ed. Atlas. São Paulo, 2008.

GOMES, M. C.; DA POIAN, A. T.; GOLDBACH, T. Revistas de divulgação científica no ensino de ciências e biologia: contribuições e limitações de seu uso. In: III ENECiências - Encontro Nacional de Ensino de Ciências da Saúde e do Ambiente. Atas... Niterói, 2012.

GONÇALVES, E. M.; Divulgação científica da pesquisa brasileira: um diagnóstico da revista Scientific American Brasil. Contemporanea, v. 6, n. 1, Jun. 2008.

LEGEY, A. P.; JURBERG, C.; COUTINHO, C. M. L. M.; Educação Científica na Mídia Impressa Brasileira: avaliação da divulgação de biologia celular em jornais e revistas selecionados. Alexandria Revista de Educação em Ciência e Tecnologia, v. 2, n. 3, p. 35-52, nov. 2009. 
LEITE, B. Biotecnologias, clones e quimeras sob controle social: missão urgente para a divulgação científica. São Paulo em Perspectiva, v. 14, n. 3, p. 40-46, 2000.

LINHARES, S. e GEWANDSZNAJDER, F.; Biologia Hoje. 2 ed. Ática. São Paulo, 2014.

LUNA, E. J. A.; SILVA JR., J. B.; Doenças transmissíveis, endemias, epidemias e pandemias. In: Fundação Oswaldo Cruz. A saúde no Brasil em 2030 - prospecção estratégica do sistema de saúde brasileiro: população e perfil sanitário. v. 2. Rio de Janeiro: Fiocruz/Ipea/Ministério da Saúde/Secretaria de Assuntos Estratégicos da Presidência da República, 2013.

MARTINS, I.; NASCIMENTO, T. G.; ABREU, T. B.; Clonagem na sala de aula: um exemplo do uso didático de um texto de divulgação científica. Investigações em Ensino de Ciências, v. 9, n. 1, p. 95-111, 2004.

PRAIA, J.; GIL-PEREZ, D.; VILCHES, A.; O papel da natureza da ciência na educação para a cidadania. Ciênc. educ. Bauru, v. 13, n. 2, p. 141-156, Ago. 2007.

SCORSOLINI-COMIN, F.; Produção e divulgação científica: um compromisso em constante atualização. Rev. SPAGESP, Ribeirão Preto, v. 13, n. 1, p. 1-4, 2012. Disponível em: <http://pepsic.bvsalud.org/scielo.php?script=sci_arttext\&pid=S1677$29702012000100001 \& \operatorname{lng}=$ pt\&nrm=iso>. Acessado em: 12 de maio de 2016.

SILVA, L. H. P.; Ciências biológicas e biotecnologia: realidades e virtualidades. São Paulo em perspectiva, v. 14, n. 3, 2000.

TORRES, B. B. Educação em Ciências Biológicas. In: $\mathbf{1 8}^{\circ}$ Encontro sobre temas de Genética e Melhoramento. Anais... Piracicaba, 2001.

VALÉRIO, M.; BAZZO, W. A. O papel da divulgação científica em nossa sociedade de risco: em prol de uma nova ordem de relações entre ciência, tecnologia e sociedade.

Revista Iberoamericana de Ciencia, Tecnología, Sociedad e Innovación. n. 7, 2006. Disponível em: <http://www.oei.es/revistactsi/numero7/articulo02b.htm>. Acesso em: 12 fev. 2016.

ZAMBONI, L. M. S. Cientistas, jornalistas e a divulgação científica: subjetividade e heterogeneidade no discurso da divulgação científica. Campinas. Autores Associados, 2001. 